\title{
BUILDING COMMITMENT THROUGH \\ STRATEGIC INVOLVEMENT: \\ The Mediating Role of Procedural Justice
}

\author{
Mary Lemons \\ University of Tennessee-Martin \\ Martin, TN \\ J. Barry Gilmore \\ The University of Memphis \\ Memphis, TN
}

\begin{abstract}
Although many researchers assert the importance of involvement in strategic planning for gaining employee commitment to strategic formulation and implementation, neither the existence of this relationship nor the strength of the effect of involvement on commitment is clear. Using a sample of top-, middle-, and lower-level managers, this study found significant results which suggest that procedural justice partially mediates the relationship between strategic involvement and commitment.
\end{abstract}

\section{Building Commitment Through Strategic Involvement: The Mediating Role of Procedural Justice}

Strategic management theorists assert that planning is an essential tool for managers (Herold, 1972; Malik \& Karger, 1975; Oswald, Mossholder, \& Harris, 1994, 1997; Thune \& House, 1970). However, most planning research examines the differences in performance between planners and non-planners with little attention given to the actual planning process (Rhyne, 1986). This is an unfortunate occurrence as much criticism revolves around the manner in which planning is carried out (Rhyne, 1986). In addition, researchers suggest the importance of involvement in the strategic planning process for obtaining commitment to strategic formulation and implementation (Oswald, et al., 1994). Nevertheless, little empirical research addresses why or how strategic involvement may enhance employee commitment. Because "successful strategy formulation and implementation require the commitment and involvement of managers at all levels" (Oswald et al., 1994: 477), it is important that researchers fully understand the relationship between these variables (Mintzberg, 1990; Rhyne, 1986).

One concept that may partially explain the relationship between strategic involvement and organizational commitment is procedural justice. Procedural justice in strategic planning refers to the perceived fairness of the procedures 
used during the planning process (Greenberg, 1990). Although labeled "process control" or "voice," involvement is a key component in procedural justice perceptions (Bies, 1987; Greenberg, 1990; Leung \& Li, 1990). Process control refers to the opportunity participants have in communicating their views and opinions in a decision-making process. The greater the process control allowed to participants, the more likely they regard the decision-making procedures as fair (Leung $\& \mathrm{Li}, 1990)$. Thus, as employee involvement in the planning process increases, perceptions of procedural justice in strategic planning should also increase.

Most procedural justice research has examined the effect of justice perceptions on employee attitudes, revealing that procedural justice affects many important outcomes, such as employee commitment (Robertson, Iles, Gratton, \& Sharpley, 1991; Sweeney \& McFarlin, 1993), job satisfaction (Dailey \& Kirk, 1992; McFarlin \& Sweeney, 1992), pay satisfaction (Folger \& Konovsky, 1989; McFarlin \& Sweeney, 1992; Sweeney \& McFarlin, 1993), intent to turn over (Dailey \& Kirk, 1992), and post-hire attitudes and behaviors (e.g., recommendation intentions) (Gilliland, 1993, 1994). One area that has received little attention, however, concerns the importance of justice perceptions in strategic planning.

Because researchers suggest that justice in the workplace may be a stronger predictor of behavioral manifestations (e.g., intent to turnover) than core work attitudes (Dailey \& Kirk, 1992), it is important that companies recognize the factors that can lead to perceptions of workplace justice and their potential impact. Thus, the purpose of this study is to examine the significance of procedural justice in the relationship between involvement in strategic planning and organizational commitment. Specifically, it is proposed that procedural justice acts as a partial mediator in the relationship between these variables.

\section{Theoretical Foundation}

\section{Strategic Involvement and Organizational Commitment}

The significance of both strategic involvement and organizational commitment have been examined in previous literature (Floyd \& Wooldridge, 1992; Guth \& MacMillan, 1986; Kim \& Mauborgne, 1993; Oswald et al., 1994; Rhyne, 1986; Wooldridge \& Floyd, 1990). Organizational commitment refers to the strength of employees' identification with and involvement in the organization. Commitment may be characterized by three factors: (1) acceptance of the goals and values of the organization; (2) the willingness to exert effort for the sake of the organization; and (3) the desire to remain a member of the organization (Cammann, Fichman, Jenkins, \& Klesh, 1983). Research indicates that low organizational commitment may contribute to high employee turnover (Blau \& Boal, 1989; Gaertner \& Nollen, 1989; Meyer \& Allen, 1991; Shore \& Martin, 1989; Steers, 1977). Factors influencing organizational commitment can be grouped into three categories: personal characteristics, such as age or education; job characteristics, 
such as task identity or feedback; and work experiences, such as group attitudes or organizational dependability (Steers, 1977).

Many studies have examined the personal characteristics and job characteristics that might influence organizational commitment. For example, some researchers have found age to be positively related to commitment (Steers, 1977) while Marsh \& Mannari (1977) conclude that age, seniority, and job prestige are positively related to commitment. Job characteristics that have been connected to organizational commitment include job involvement (Blau \& Boal, 1989), the opportunity for optional social interaction while completing tasks (Steers, 1977), and job scope (Marsh \& Mannari, 1977). Job involvement particularly affects work-related attitudes such as organizational commitment by playing a significant role in determining how employees view the psychological contract between themselves and the organization (Farrell \& Stamm, 1988; Hackett \& Guion, 1985).

Work experiences can also be "a major socializing force" that impacts the psychological attachment an employee might feel toward an organization (Steers, 1977:48). For example, group attitudes toward an organization and perceptions of personal investment and personal importance to an organization may influence commitment, whereas organizational dependability and trust are also important factors. In addition, rewards and the realization of expectations are positively related to organizational commitment, and a significant negative relationship exists between commitment and racial and sexual discriminatory behaviors (Niebuhr, 1992).

Research suggests that involving managers at all organizational levels in the strategic planning process may result in higher organizational commitment (Oswald et al., 1994). For example, involvement in strategic planning may increase employees' psychological attachment to the organization by increasing their organizational commitment, job satisfaction, and job involvement (Oswald et al., 1994). Dess (1987) asserts that involvement also enhances commitment to strategic implementation by providing opportunities for shared understanding. Commitment may be enhanced by involvement through the disclosure of strategic information and strategic preferences (Floyd \& Wooldridge, 1992). Finally, a lack of strategic commitment may cause managers not to give implementation the attention necessary for success, while in some cases low commitment may cause managers to actually sabotage organizational strategy (Guth \& MacMillan, 1986). Thus, organizational commitment may influence compliance of top managers regarding corporate strategies (Kim \& Mauborgne, 1993).

Research indicates that employee involvement in the strategic planning process may influence levels of employee commitment; however, neither the existence of this relationship nor the strength of the effect of involvement on commitment is clear. Because "mediators speak to how or why such effects occur" (Baron \& Kenny, 1986: 1176), this study proposes that procedural justice partially mediates this relationship. Procedural justice may be said to be a partial mediator if it partially accounts for the relation between involvement and commitment (Baron \& Kenny, 1986). Should this proposition prove true, the results herein should 
provide a deeper understanding of the importance of involvement for successful strategic planning.

\section{Procedural Justice: The Partial Mediation Role}

Procedural justice emerged as an attempt to describe the role of fairness in the workplace (Greenberg, 1990). Procedural justice, originally proposed by Thibaut and Walker as the result of a series of reactions to dispute-resolution processes, refers to the fairness or equity of the procedures used to make decisions or distribute rewards. As additional research was conducted in this area (for reviews, see Lind \& Tyler, 1988; Tyler, 1987), it became clear that Thibaut and Walker's findings were reflective of a more general tendency across a variety of settings. Recent research in the area of procedural justice has examined a variety of themes, including survivors' reactions to layoffs (Brockner et al., 1994), employee reactions to selection decisions (Gilliland, 1993, 1994), employee reactions to pay freezes (Schaubroeck, May, \& Brown, 1994) and the effect of justice perceptions on organizational citizenship behaviors (Bazerman, Schroth, Shah, Diekmann, \& Tenbrunsel, 1994).

Strategic involvement may be important to perceptions of procedural justice because involvement relates to the procedural variable of process control. Process control (or "voice") refers to allowing participants who might be affected by a decision to present information relevant to that decision (Folger \& Greenberg, 1985). Procedures granting some control over the process and outcome attainment tend to be perceived by participants as fairer than procedures that deny process control (Greenberg, 1990). When the process is considered fair, participants are more likely to accept the authority's decision (Lind, Kulik, Ambrose, \& de Vera Park, 1993). In addition, when decision-makers communicate a justification for the decision reached and the decision-maker is considered sincere, participants view the process as more fair (Bies, 1987; Richard \& Kirby, 1997).

In the case of strategic planning, procedures used to make decisions include obtaining input from lower and middle-level managers by conducting formal or informal meetings or by requesting oral or written reports. Employees allowed to participate in the formulation of strategic plans for the organization because of these procedures are more committed to and accepting of the final decisions regarding the plans for the organization (Korsgaard, Schweiger, \& Sapienza, 1995; Oswald, Mossholder, \& Harris, 1997). Because commitment is necessary for managerial compliance, this can be especially important for successful strategic implementation (Guth \& MacMillan, 1986).

In their study of global strategy implementation, Kim \& Mauborgne (1991) found that procedural justice of the global strategy formulation process affects commitment, trust, and social harmony as well as outcome satisfaction in subsidiary top managers. Korsgaard and colleagues found that perceived fairness also partially mediates the effects of consideration and influence on decision commitment (Korsgaard et al., 1995). Thus, procedural justice may enhance compliance 
directly and indirectly through the attitudes of commitment, trust, and outcome satisfaction (Kim \& Mauborgne, 1993). On the other hand, perceptions of unfair procedures in strategic planning caused by a lack of involvement, may lower organizational commitment which, in turn, may lead to negative organizational outcomes such as absenteeism and turnover (Aquino, Griffeth, Allen, \& Hom, 1997; Hackett \& Guion, 1985; Marsh \& Mannari, 1977).

Previous studies have established a positive relationship between procedural justice and organizational commitment (Dailey \& Kirk, 1992; Konovsky \& Folger, 1987; Sweeney \& McFarlin, 1993), as well as a positive relationship between strategic involvement and organizational commitment (Kim \& Mauborgne, 1991, 1993; Korsgaard et al., 1995; Oswald et al., 1994). This research is based on direct effects, whereby procedural justice is hypothesized as a direct antecedent of commitment and involvement is hypothesized as a direct antecedent of organizational commitment. Little empirical research exists, however, to support the mediating role, or indirect effects, of procedural justice in the relationship between strategic involvement and organizational commitment. On the other hand, the studies mentioned above offer indirect support (Kim \& Mauborgne, 1991, 1993; Korsgaard et al., 1995; Oswald et al., 1994).

This study proposes that procedural justice is (1) an important partial mediator of the effects of strategic involvement on organizational commitment and (2) a more potent predictor of organizational commitment than strategic involvement. This is not to imply that the direct effect of strategic involvement on organizational commitment is insignificant; rather, the proposition is that the direct effect of strategic involvement on organizational commitment after controlling for procedural justice is mostly marginal compared with its "before" effects (e.g., before partialing the mediated effect of procedural justice). In this sense, procedural justice partially mediates the relationship between strategic involvement and organizational commitment. The following hypothesis was developed to test this proposed relationship.

Hypothesis 1: Perceptions of procedural justice in strategic planning partially mediate the relationship between strategic involvement and organizational commitment.

\section{Method}

\section{Subjects}

The sample for this study consisted of top-, middle-, and lower-level management employees (deans, department chairs, and administrators) working fulltime at two large southern universities. The questionnaires were sent via campus mail along with a letter explaining the study and a self-addressed return envelope. Of the 434 distributed questionnaires, 204 were returned ( 76 female, 129 male) for a response rate of 47 percent. Although the letter explained that the survey 
was confidential, several respondents elected to use their own return envelopes, emphasizing the sensitive nature of the data. An examination of the data revealed that 63 percent of the respondents were over the age of 40,86 percent had worked at the universities for three years or more, and 72 percent held graduate degrees. Of the 204 respondents, 46 held upper-level positions, 99 held middle-level positions and 60 held lower-level positions.

\section{Measures}

\section{Strategic Involvement}

To measure strategic involvement, a modified version of Oswald et al.'s (1994) involvement scale was used. This scale makes four statements regarding the extent of employees' involvement in the strategic planning process within their organization. Subjects were asked to rate the extent they agree or disagree with each statement on a seven-point Likert scale ( $1=$ strongly disagree, $7=$ strongly agree). One of the statements is reverse-coded to reduce the possibility of response set bias. Strategic plans were described to the respondents in this study as plans formulated to achieve the goals of the organization (e.g., new markets, firm growth). An example of the scale format is: "Currently, I am greatly involved in strategic planning for the organization." Using Cronbach's alpha, reliability for this scale was .90 in this study.

\section{Procedural Justice}

To measure procedural justice, a five-item scale was developed using a format similar to the Price \& Mueller (1986) Distributive Justice index. The items were based on prior research in this area and included statements regarding the extent of communication, consistency, opportunity to refute the views of their superiors, and feedback. A similar study examining the mediating role of procedural justice used the same format and obtained reliability of .96 (Korsgaard et al., 1995). Procedures used during the strategic planning process were broadly defined, with meetings and written reports listed as examples. An example of the item format is: "Considering the extent of communication between you and your superior regarding strategic plans for your organization, how fair are the procedures used in strategic planning?" ( $1=$ very unfair, $5=$ =very fair). Using Cronbach's alpha, reliability for the scale in this study was .94 .

\section{Organizational Commitment}

Organizational commitment was assessed using Mowday \& Steers' (1979) Organizational Commitment Questionnaire (OCQ). This instrument consists of fifteen items, nine which are positively scored and six which are negatively scored. Again, reverse-coding reduces the possibility of response set bias. The items ask workers to express their agreement or disagreement with various statements (e.g., "I am willing to put in a great deal of effort beyond that normally expected in 
order to help this organization be successful"), using seven-point scales ( $1=$ strongly disagree, $7=$ strongly agree). Reliability for the scale in this study using Cronbach's Alpha was .89, which was comparable to previous studies.

\section{Analysis and Results}

Table 1 shows the descriptive statistics, reliabilities, and correlations for the study's variables. With mediation models, the independent variable (strategic involvement) is assumed to cause the mediator (perceptions of procedural justice); thus, these variables should be highly correlated (Alwin \& Hauser, 1975; Baron \& Kenny, 1986; James \& Brett, 1984; Rozeboom, 1956). As can be seen in Table 1 , the correlation between these variables is $.61(p<.001)$, which does indicate possible mediation. On the other hand, the dependent variable (organizational commitment) must not cause the mediator variable (justice perceptions). Theory indicates that these are different and independent constructs (Korsgaard et al., 1995; McFarlin \& Sweeney, 1992). In addition, Sweeney and McFarlin (1993) used path analysis to test the relationship between justice and commitment. The findings of these researchers also suggest the possibility of a mediational chain in the hypothesized direction.

Generally speaking, to test a mediational hypothesis, it has been suggested that one should estimate a series of three regression models (Baron \& Kenny, 1986). First, the mediator variable must be regressed on the independent variable. Second, the dependent variable is regressed on the independent variable. Third, the dependent variable is regressed on both the mediator and the independent variable. These three equations provide the test for mediation. To provide support for the mediation model, the independent variable must affect the mediator in the first equation, the independent variable must affect the dependent variable in the second equation, and the mediator must affect the dependent variable in the third equation. When these conditions hold in the predicted direction, the effect of the independent variable on the dependent variable must be less in the third equation than in the second equation. For perfect mediation, this relationship will vanish entirely; with partial mediation, the independent variable still affects the dependent variable, but in a significantly reduced fashion (Venkatraman, 1989).

Table 2 presents a more dynamic picture of the relationship among this study's variables. Because managerial level and tenure might be expected to covary with involvement and commitment, the Scheffe multiple range procedure was employed. The only significant difference revealed was between managerial level and level of involvement, with higher involvement levels reported by upper-level and middle-level managers than by lower-level managers. Thus, the calculation of each equation included level of management as a control variable (see footnote at the bottom of Table 2).

Using a series of multiple linear regression models, three equations were estimated. 
Table 1

Mean Std.Dev. Rel. Commit Justice Involve

$\begin{array}{lllll}\text { Commit } & 5.31 & .96 & .89 & 1.00\end{array}$

$\begin{array}{llllll}\text { Justice } & 3.69 & 1.03 & .94 & .50^{* * *} & 1.00\end{array}$

$\begin{array}{lllllll}\text { Involve } & 5.34 & 1.02 & .90 & .52^{* * *} & .61^{* * *} & 1.00\end{array}$

*** significant at the .001 level, two-tailed test

\section{Table 2}

F Value ${ }^{1} \quad \mathbf{R}^{2} \quad$ Beta of Involvement

$\begin{array}{llll}\text { Equation 1 } & \mathrm{F}_{(2.202)}=46.82^{* * *} & .31 & .40 \\ \text { Equation 2 } & \mathrm{F}_{(2,202)}=26.68 * * * & .22 & .30 \\ \text { Equation 3 } & \mathrm{F}_{(3,201)}=23.70^{* * *} & .29 & .19\end{array}$

*** significant at the .001 level, two-tailed test

Equation 1 = Strategic Involvement Procedural Justice

Equation 2 = Strategic Involvement Organizational Commitment

Equation 3 = Strategic Involvement Procedural Justice Organizational Commitment

1 $\quad \mathrm{E}$ and $\mathrm{R}^{2}$ values are reported after controlling for managerial level.

First the mediator variable (procedural justice) was regressed on the independent variable (strategic involvement) to yield an $R^{2}$ of .31 , which was statistically significant $(\mathfrak{p} .<.001)$. Thus, strategic involvement accounted for 31 percent of the variance in procedural justice. Second, organizational commitment was regressed on strategic involvement to yield an $R^{2}$ of .22, which was also significant (p. $<$ .001 ). This equation indicated that strategic involvement accounted for 22 percent of the variance in organizational commitment. Finally, organizational commitment was regressed on both procedural justice and strategic involvement to yield an $R^{2}$ of .29 , which was statistically significant (p. $<.001$ ). 
In a mediation model, the effect of the independent variable on the dependent variable should increase when the mediator is included in the equation (Baron $\&$ Kenny, 1986). The increase in $\mathrm{R}^{2}$ when the mediator was included (from .22 to .29) suggests that procedural justice may act as a partial mediator in the relationship between strategic involvement and organizational commitment in this study. In addition, an examination of the Beta coefficients of strategic involvement reveals a decrease in the strength of the relationship between strategic involvement and organizational justice when procedural justice is included as a mediator (without the mediator, Beta for Involvement $=.30$; with the mediator included, Beta for Involvement $=.19$ ). If the relationship had disappeared completely, one might infer that procedural justice behaves as a total mediator in this relationship. However, since a small effect was present after holding procedural justice constant, procedural justice acts as a partial mediator in the relationship between strategic involvement and organizational commitment in this study. Thus, the results of this analysis provide support for our hypothesis.

\section{Discussion}

The hypothesis stating that perceptions of procedural justice in strategic planning partially mediates the relationship between strategic involvement and organizational commitment was supported in this study. These results support previous research suggesting that strategic involvement may affect managers' psychological attachment to their organizations (Oswald et al., 1994). Specifically, as involvement in the strategic planning process increases, organizational commitment may be positively influenced. This is an important finding for managers, since organizational commitment has been associated with many important outcomes, such as employee turnover and absenteeism (Blau \& Boal, 1989; Gaertner \& Nollen, 1989; Meyer \& Allen, 1991; Shore \& Martin, 1989; Steers, 1977). In addition, the results of this study indicate that the relationship between strategic involvement and organizational commitment is largely due to the perception of procedural justice in the planning process.

The structure of universities, with diverse groupings of disciplines and departments residing interdependently under one organizational roof, demands the inclusion of managers in the planning process (Lipman-Blumen, 1998). The result is higher expectations of significant involvement by university employees. Further, in this changing era of diversity and interdependence, Lipman-Blumen (1998) suggests business leaders may be more successful engaging in patterns of "connective leadership"rather than traditional forms of authoritarian leadership. Thus, the results of this study hold implications for practitioners wishing to implement this leadership style.

First, with the recent influx of discrimination cases brought against organizations, managers are becoming more aware of fairness issues in the workplace (Peterson \& Danehower, 1994). Due to an interest in the glass ceiling for women 
(Morrison \& Von Glinow, 1990), as well as arguments regarding the fairness of affirmative action programs (Heilman, 1994; Kravitz \& Platonia, 1993), organizational justice will continue to be an issue of great concern for a large number of companies wishing to promote equality in an era of spiraling discrimination suits and workplace diversity. Thus, managers wishing to avoid expensive legislation should be concerned with ways to increase their employees' perceptions of organizational justice. Involvement in the planning process may be one avenue to this result.

Second, there is a compelling amount of evidence suggesting that organizational justice can have an impact on many organizational outcomes in addition to commitment (Dailey \& Kirk, 1992; Folger \& Konovsky, 1989; McFarlin \& Sweeney, 1992). Therefore, one way to influence job satisfaction, pay satisfaction, and recommendation intentions may be for managers to involve employees in the strategic planning process.

Finally, Hart (1992) suggests that strategy-making be viewed as an organizationwide phenomenon. However, simply involving employees in the process may not provide the commitment needed for company success. While practitioners have been advised that involvement may affect commitment, they should also be informed that, although involvement may be necessary for employee commitment, it may also be insufficient. In addition to involving managers in the planning process, organizations must ensure that the involvement process is perceived as fair. Because justification and sincerity increase the likelihood of fairness perceptions (Bies, 1987), decision-makers should present logical arguments for their planning decisions in a sincere fashion that convinces employees of the fairness of the planning process. Without the fairness dimension, involvement may be a wasted management effort.

For researchers, the results of this study should provide a deeper understanding of why involvement in strategic planning affects outcome variables such as organizational commitment, an important construct in controlling other important variables, such as employee turnover (Blau \& Boal, 1989; Gaertner \& Nollen, 1989; Meyer \& Allen, 1991; Shore \& Martin, 1989; Steers, 1977). This study also underscores recent admonitions for organizational researchers to duplicate laboratory studies to determine the generalizability of previous findings (Cropanzano \& Folger, 1989).

Several limitations are inherent in this study. First, because the data collected were self-reported, some of the observed relationships may be exaggerated due to common-method bias or the priming effect (Head et al., 1988). However, the results of a partial-correlation test did not indicate this to be a critical issue. Partial correlation has been determined to be a stronger test for controlling selfreport problems than the Harman's one-factor test (Podsakoff \& Organ, 1986). Nonetheless, future research might address the problem of common-method variance by relying on multiple methods of data collection, or by collecting data at different periods of time. 
Second, while care was taken to ensure that only managers completed the questionnaires, another limitation of this study was the sample composition. The use of university employees may have caused an overestimation of the importance of strategic planning, thus resulting in a stronger significance level. These individuals may feel more strongly about workplace involvement, as well as the planning function, than a more diverse group of employees( Lipman-Blumen, 1998). Additionally, unlike cross-sectional studies, the use of two non-profit organizations limits the generalizability of the results herein. Without future research testing a variety of organizations in the private sector, it may be unwise to apply the results of this study to the general population. In addition, the sample was $90 \%$ Caucasian. A more diverse group might yield different results. On the other hand, because previous research indicates that most individuals feel justice is an important issue (Witt \& Nye, 1992), future research should confirm rather than refute the findings herein.

Finally, with regard to limitations based on the sample composition, the definition of the planning process may be perceived differently by university managers than by managers in the public sector. On the other hand, people's perceptions are their reality. Thus, it is the perception of being involved in the strategic planning process that produces perceptions of fairness. Even though public-sector respondents may hold different perceptions of what the planning process entails in their organizations, it is their perception of being involved that really counts, and not the definition of the planning process. However, future research should be conducted using public-sector organizations.

Implications for future research also include examining the mediating role of procedural justice in other strategic relationships. For example, the relationship between strategic involvement and implementation compliance (Guth \& MacMillan, 1986) may be strengthened by adding procedural justice to the model. Employee participation in strategic planning may increase feelings of "voice" in decisions, resulting in increased compliance during the strategic implementation stage (Kim \& Mauborgne, 1993). Additionally, because involvement explained a high percentage of the variance in procedural justice, outcome variables other than organizational commitment should be investigated (e.g., absenteeism, turnover) to determine whether they might also be affected using involvement as an independent variable and perceived fairness as a mediator.

To summarize, this research investigates a long-neglected area of strategic management, the actual planning process (Oswald et al., 1994; Rhyne, 1986). While research examining differences in performance between planners and nonplanners was the first step in establishing the importance of strategic planning, it is now time to develop a deeper understanding of how planning should be carried out (Rhyne, 1986). This study provides support for the mediating role of procedural justice in the relationship between involvement and organizational commitment and should provide an impetus for future research in this area. 


\section{References}

Alwin, D.F., \& Hauser, R.M. (1975). The Decomposition of Effects in Path Analysis. American Sociological Review, 40: 37-47.

Aquino, K., Griffeth, R.W., Allen, D.G., \& Hom, P.W. (1997). Integrating Justice Constructs into the Turnover Process: A Test of a Referent Cognitions Model. Academy of Management Joumal. 40 (5): 1208-1227.

Baron, R.M., \& Kenny, D.A. (1986). The Moderator-mediator Variable Distinction in Social Psychological Research: Conceptual, Strategic, and Statistical Considerations. Journal of Personality and Social Psychology. 51(6): 1173-1182.

Bazerman, M.H., Schroth, H.A., Shah, P.P., Diekmann, K.A., \& Tenbrunsel, A.E. (1994). The Inconsistent Role of Comparison Others and Procedural Justice in Reactions to Hypothetical Job Descriptions: Implications for Job Acceptance Decisions. Organizational Behavior and Human Decision Processes, 60: 326-352.

Bies, R.J. (1987). Beyond "Voice": The Influence of Decision-maker Justification and Sincerity on Procedural Faimess Judgment. Representative Research in Social Psychology. 17(1): 3-14.

Blau, G., \& Boal, K. (1989). Using Job Involvement and Organizational Commitment Interactively to Predict Tturnover.Journal of Management. 15(1): 115-127.

Brockner, J., Konovsky, M., Cooper-Schneider, R., Folger, R., Martin, C., \& Bies, R.J. (1994). Interactive Effects of Procedural Justice and Outcome Negativity on Victims and Survivors of Job Loss. Academy of Management Journal. 37 (2): 397-409.

Cammann, C., Fichman, M., Jenkins, G.D., \& Klesh, J.R. (1983). In J.L. Price \& C.W. Mueller (eds.) Handbook of Organizational Measurement, 1986. Marshfield, MA: Pitman Publishing.

Cropanzano, R., \& Folger, R. (1989). Referent Cognitions and Task Decision Autonomy: Beyond Equity Theory. Journal of Applied Psychology, 74 (2): 293-299.

Dailey, R.C., \& Kirk, D.J. (1992). Distributive and Procedural Justice as Antecedents of Job Dissatisfaction and Intent to Turnover. Human Relations, 45 (3): 305-317.

Dess, G.G. (1987). Consensus on Strategy Formulation and Organizational Performance: Competitors in a Fragmented Industry. Strategic Management Journal. 8: 259-277.

Farrell, D., \& Stamm, C.L. (1988). Meta-analysis of the Correlates of Employee Absence. Human Relations. 41: 211-227.

Floyd, S.W., \& Wooldridge, B. (1992). Managing Strategic Consensus: The Foundation of Effective Implementation. Academy of Management Executive. 6 (4): 27-39. 
Folger, R., \& Greenberg, J. (1985). Procedural Justice: An Interpretational Analysis of Personnel Systems. Research in Personnel and Human Resources Management, 3: 141-183.

Folger, R., \& Konovsky, M.A. (1989). Effects of Procedural and Distributive Justice on Reactions to Pay Raise Decisions. Academy of Management Journal. 32 (1): 115 130.

Gaertner, K.N., \& Nollen, S.D. (1989). Career Experiences, Perceptions of Employment Practices, and Psychological Commitment to the Organization. Human Relations, 42 (11): $975-991$.

Gilliland, S.W. (1993). The Perceived Fairness of Selection Systems: An Organizational Justice Perspective. Academy of Management Review, 18 (4): 694-734.

Gilliland, S.W. (1994). Effects of Procedural and Distributive Justice on Reactions to a Selection System. Journal of Applied Psychology. 79 (5): 691-701.

Greenberg, J. (1990). Organizational Justice: Yesterday, Today, and Tomorrow. Journal of Management. 16 (2): 399-432.

Guth, W.D., \& MacMillan, I.C. (1986). Strategy Implementation Versus Middle Management Self-interest. Strategic Management Journal. 7: 313-327.

Hackett, R.D., \& Guion, R.M. (1985). A Reevaluation of the Absenteeism-job Satisfaction Relationship. Organizational Behavior and Human Decision Processes, 35: 340 381.

Hart, S.L. (1992). An Integrative Framework for Strategy-making Processes. Academy of Management Review, 17 (2): 327-351.

Head, T.C., Griffin, R.W., Bateman, T.S., Lohman, L., \& Yates, V.L. (1988). The Priming Effect in Task Design Research. Journal of Management. 14(1): 33-39.

Heilman, M.E. (1994). Affirmative Action: Some Unintended Consequences for Working Women. Research in Organizational Behavior. 16: 125-169.

Herold, D.M. (1972). Long-range Planning and Organizational Performance: A CrossValidation Study. Academy of Management Journal. 3: 91-102.

James, L.R., \& Brett, J.M. (1984). Mediators, Moderators, and Tests for Mediation. Journal of Applied Psychology, 69(2): 307-321.

Kim, W.C., \& Mauborgne, R.A. (1993). Procedural Justice, Attitudes, and Subsidiary Top Management Compliance with Multinationals' Corporate Strategic Decisions. Academy of Management Joumal. 36(3): 502-526. 
Kim, W.C., \& Mauborgne, R.A. (1991). Implementing Global Strategies: The Role of Procedural Justice. Strategic Management Journal, 12: 125-143

Konovsky, M.A., \& Folger, R. (1987). Relative Effects of Procedural and Distributive Justice on Employee Attitudes. Representative Research in Social Psychology, 17(1): 15-24.

Korsgaard, M.A., Schweiger, D.M., \& Sapienza, H.J. (1995). Building Commitment, Attachment, and Trust in Strategic Decision-making Teams: The Role of Procedural Justice. Academy of Management Journal, 38 ( I): 60-84.

Kravitz, D.A., \& Platonia, J. (1993). Attitudes and Beliefs about Affirmative Action: Effects of Target and of Respondent Sex and Ethnicity. Journal of Applied Psychology, 78(6): 928-938.

Lemons, M., \& Jones, C. (1995). An Examination of the Effect of Procedural Justice in Promotion Decisions on Organizational Commitment. Paper presented at the Southwest Academy of Management meeting, Houston, TX: 104-108.

Leung, K., \& Li, W. (1990). Psychological Mechanisms of Process-control Effects. Journal of Applied Psychology. 75(6): 613-620.

Lind, E.A., Kulik, C.T., Ambrose, M., \& de Vera Park, M.V. (1993). Individual and Corporate Dispute Resolution: Using Procedural Fairness as a Decision Heuristic. Administrative Science Quarierly, 38: 224-251.

Lind, E.A., \& Tyler, T. (1988). The Social Psychology of Procedural Justice. New York: Plenum.

Lipman-Blumen, J. (1998). Connective Leadership: What Business Needs to Learn From Academe. Change, 30 (1): 49-53.

Malik, Z.A., \& Karger, D.W. (1975). Does Long-range Planning Improve Company Performance? Management Review, 9: 27-31.

Marsh, R.M., \& Mannari, H. (1977). Organizational Commitment and Turnover: A Prediction Study. Administrative Science Quarterly, 22: 57-75.

McFarlin, D.B., \& Sweeney, P.D. (1992). Distributive and Procedural Justice as Predictors of Satisfaction with Personal and Organizational Outcomes. Academy of Management Journal, 35 (3): 626-637.

Meyer, J.P., \& Allen, N.J. (1991). A Three-component Conceptualization of Organizational Commitment. Human Resource Management Review, 1 (1): 61-89.

Mintzberg, H. (1990). The Design School: Reconsidering the Basic Premises of Strategic Management. Strategic Management Journal. 11 (3): 171-195. 
Morrison, A., \& Von, Glinow, M.A. (1990). Women and Minorities in Management. American Psychologist. 45 (2): 200-208.

Mowday, R., \& Steers, R.M. (1979). In J.L. Price \& C.W. Mueller (eds.) Handbook of Qrganizational Measurement, 1986. Marshfield, MA: Pitman Publishing.

Niebuhr, R.E. (1992). Measuring Equal Opportunity Climate in Organizations: An Examination of the Relationship to Group Cohesion and Group Performance. Paper presented at the Southern Management Association in New Orleans, LA.

Oswald, S.L., Mossholder, K.W., \& Harris, S.G. (1994). Vision Salience and Strategic Involvement: Implications for Psychological Attachment to Organization and Job. Strategic Management Journal, 15: 477-489.

Oswald, S.L., Mossholder, K.W., \& Harris, S.G. (1997). Relations between Strategic Involvement and Managers' Perceptions of Environment and Competitive Strengths. Group and Organization Management. 22 (3): 343-365.

Peterson, R.C., \& Danehower, V.C. (1994). Judicial Decisions in Promotion Selection in Employment: An Empirical Study of Discrimination Cases. Paper presented at the Southwest Academy of Management meeting in Dallas, Texas.

Podsakoff, P.M., \& Organ, D.W. (1986). Self-reports in Organizational Research: Problems and Prospects. Journal of Management. 12 (4): 531-544.

Price, J.L., \& Mueller, C.W. (1986). Handbook of Organizational Measurement, Marshfield, MA: Pitman.

Rhyne, L.C. (1986). The Relationship of Strategic Planning to Financial Performance. Strategic Management Journal, 7: 423-436.

Richard, O.C., \& Kirby, S.L. (1997). African American's Reactions to Diversity Programs: Does Procedural Justice Matter? Journal of Black Psychology. 23 (4): 388397.

Robertson, I., Iles, P., Gratton, L., \& Sharpley, D. (1991). The Impact of Personnel Selection and Assessment Methods on Candidates. Human Relations, 44: 963-982.

Rozeboom, W.W. (1956). Mediation Variables in Scientific Theory. Psychological Review, 63 (4): 249-264.

Schaubroeck, J., May, D.R., \& Brown, F.W. (1994). Procedural Justice Explanations and Employee Reactions to Economic Hardship: A Field Experiment. Journal of Applied Psychology, 79 (3): 455-460. 
Shore, L.M., \& Martin, H.J. (1989). Job Satisfaction and Organizational Commitment in Relation to Work Performance and Turnover Intentions. Human Relations, 42 (7): 625-638.

Steers, R.M. (1977). Antecedents and Outcomes of Organizational Commitment. Administrative Science Quarterly. 22: 46-56.

Sweeney, P.D., \& McFarlin, D.B. (1993). Workers' Evaluations of the "Ends" and the "Means": An Examination of Four Models of Distributive and Procedural Justice. Organizational Behavior and Human Decision Processes, 55: 23-40.

Thune, S.S., \& House, R.J. (1970). Where Long-range Planning Pays Off. Business Horizons, 8: 81-87.

Tyler, T.R. (1987). Procedural Justice Research. Social Justice Research, 1: 41-66.

Venkatraman, N. (1989). The Concept of Fit in Strategy Research: Toward Verbal and Statistical Correspondence. Academy of Management Review, 14 (3): 423-444.

Witt, L.A., \& Nye, L.G. (1992). Gender and the Perceived Relationship Between Perceived Fairness of Pay or Promotion and Job Satisfaction. Journal of Applied Psychology. 77 (6): 910-917.

Wooldridge, B., \& Floyd, S.W. (1990). The Strategy Process, Middle Management Involvement, and Organizational Performance. Strategic Management Journal, 11: 231241. 


\section{Appendix \\ Modified Strategic Involvement Questionnaire}

This section makes statements about the extent of your involvement in the strategic planning that occurs within your organization. Strategic plans are formulated to achieve the goals of the organization (e.g., new markets, firm growth). How much do you agree or disagree with each statement? Please respond by circling the appropriate number.

1. Currently, I am greatly involved in strategic planning for the organization.

\begin{tabular}{ccccccc} 
Strongly & Moderately & \multicolumn{2}{c}{ Slightly Neither Disagree } & Slightly & Moderately & Strongly \\
Disagree & Disagree & Disagree & Nor Agree & Agree & Agree & Agree \\
1 & 2 & 3 & 4 & 5 & 6 & 7
\end{tabular}

2. My job requires that I think about the long-term future of my organization.

\begin{tabular}{ccccccc} 
Strongly & Moderately & \multicolumn{2}{c}{ Slightly Neither Disagree Slightly } & Moderately & Strongly \\
Disagree & Disagree & Disagree & Nor Agree & Agree & Agree & Agree \\
1 & 2 & 3 & 4 & 5 & 6 & 7
\end{tabular}

3. I am greatly involved in strategic planning for my organization at the present time.

\begin{tabular}{ccccccc} 
Strongly & Moderately & \multicolumn{2}{c}{ Slightly Neither Disagree Slightly } & Moderately & Strongly \\
Disagree & Disagree & Disagree & Nor Agree & Agree & Agree & Agree \\
1 & 2 & 3 & 4 & 5 & 6 & 7
\end{tabular}

4. I have little say in determining the long-range plans of my organization.

\begin{tabular}{ccccccc} 
Strongly & Moderately & \multicolumn{2}{c}{ Slightly Neither Disagree Slightly } & Moderately & Strongly \\
Disagree & Disagree & Disagree & Nor Agree & Agree & Agree & Agree \\
I & 2 & 3 & 4 & 5 & 6 & 7
\end{tabular}

